\title{
Substituição do farelo de soja por uréia ou amiréia na dieta de bovinos de corte confinados
}

Alexandre Vaz Pires ${ }^{(1)}$, Reinaldo Cunha de Oliveira Junior ${ }^{(1)}$, Juliano José de Resende Fernandes(1), Ivanete Susin ${ }^{(1)}$, Flávio Augusto Portela Santos( ${ }^{(1)}$, Rafael Canonenco de Araújo(1)

e Ricardo Cazerta Duarte Goulart(1)

(1)Escola Superior de Agricultura Luiz de Queiroz, Dep. de Zootecnia, Av. Pádua Dias , 11, Caixa Postal 9, CEP 13418900 Piracicaba, SP. E-mail: alvpires@esalq.usp.br, reinaldocoj@yahoo.com.br, jjrferna@esalq.usp.br, ivasusin@esalq.usp.br, fapsantos@esalq.usp.br.

Resumo - O objetivo deste trabalho foi avaliar a substituição do farelo de soja por uréia ou amiréia no desempenho de bovinos de corte em crescimento. Foram utilizados oitenta e um machos não castrados das raças Nelore (27), Canchim (27) e Holandesa (27), com peso médio inicial de $250 \mathrm{~kg}$ e idade média de 15 meses. O delineamento experimental foi o de blocos ao acaso com três tratamentos, constituídos de três animais por baia e nove baias por tratamento. Os blocos foram arranjados segundo o peso inicial e raça. Os tratamentos foram: 1) farelo de soja (FS); 2) uréia e 3) amiréia (A-150S) em dietas isoprotéicas (13,0\%) utilizando o bagaço de cana in natura (BIN) como única fonte de volumoso (20\% da MS). O consumo de matéria seca (MS) foi 6,56, 7,18 e 6,97 kg/dia; o ganho de peso vivo foi $0,889,1,114$ e 1,088 kg/dia e a conversão alimentar de 7,3, 6,5 e 6,7 kg MS/kg de ganho nos tratamentos farelo de soja, uréia e amiréia, respectivamente. O tratamento FS apresentou menor consumo e ganho de peso e também pior conversão alimentar $(\mathrm{P}<0,01)$. Os tratamentos uréia e A-150S não diferiram $(\mathrm{P}>0,05)$ entre si.

Termos para indexação: bagaço de cana-de-açúcar in natura, desempenho, PDR.

\section{Total replacement of soybean meal by urea or starea in high grain diets} for beef cattle

Abstract - The objective of this work was to evaluate the effects of replacing soybean meal by urea or starea on feedlot cattle performance. Eighty-one yearling intact males (27 Nellore, 27 Canchim and 27 Holstein) were used, with initial body weight of $250 \mathrm{~kg}$. Animals were assigned to a completely random block design according to initial weight and breed. There were nine pen/treatment with three animals/pen. Experimental treatments were: 1) soybean meal, 2) urea and 3) starea. Diets contained 13\% CP and were composed of $80 \%$ concentrate and $20 \%$ raw sugarcane bagasse. DMI was $6.56,7.18$ and $6.97 \mathrm{~kg} /$ day, average daily gain was $0.889,1.114$ and $1.088 \mathrm{~kg} /$ day and feed conversion was 7.3, 6.5 and $6.7 \mathrm{~kg} \mathrm{DM} / \mathrm{kg}$ gain for soybean meal, urea and starea, respectively. Soybean meal reduced $(\mathrm{P}<0.01)$ DMI, average daily gain and feed efficiency and there was no difference $(\mathrm{P}>0.05)$ between urea and starea treatments.

Index terms: raw sugarcane bagasse, performance, DRP

\section{Introdução}

Microrganismos ruminais são capazes de sintetizar proteína microbiana a partir de amônia e esqueleto carbônico, e o N não protéico (NNP) pode ser uma das fontes de amônia. Neste contexto, enquadram-se a amiréia e a uréia, ambas fontes de NNP.

Fontes de NNP são mais baratas que fontes de proteína considerando a mesma quantidade de nitrogênio Entretanto, a fonte de NNP mais utilizada, uréia, apresenta rápida liberação de amônia no rúmen e, dependendo da quantidade, pode exceder a capacidade de utilização dos microrganismos. Conseqüentemente, o excesso de amônia é absorvido pela parede ruminal e, uma vez na corrente sanguínea, a amônia pode ser tóxica para o animal. A parte metabolizada é transformada em uréia, envolvendo gasto de energia. A uréia produzida pode voltar (reciclagem) para o rúmen, via parede ruminal ou saliva, ou ser excretada via urina (Blaxter, 1962).

Uma fonte de NNP com liberação lenta de amônia oferece vantagens por aumentar a disponibilidade da amônia na síntese microbiana e reduzir sua toxidez (Bartley \& Deyoe, 1975). 
O processo de extrusão consiste na união da uréia com a molécula de amido gelatinizado, mediante exposição à pressão, temperatura e umidade, por um determinado tempo, obtendo-se assim a amiréia. Essa prática aumenta a velocidade de fermentação do amido no rúmen e reduz a intensidade de liberação de amônia oriunda da uréia, compatibilizando os dois fatores na síntese de proteína microbiana (Silva et al., 1994; Seixas et al., 1999).

Em épocas de preços de concentrados vantajosos dietas com alto teor de concentrado têm-se tornado viáveis economicamente, já que o ganho de peso é mais rápido, havendo redução nos custos de mão-de-obra (Bulle, et al. 2002). Neste contexto, o bagaço de canade-açúcar in natura (BIN) vem se mostrando uma boa fonte de fibra (Henrique et al., 1999; Bulle et al., 2002).

O objetivo deste trabalho foi avaliar a substituição do farelo de soja, por uréia ou amiréia, no desempenho de bovinos de corte em crescimento.

\section{Material e Métodos}

Foram utilizados 81 machos não castrados (27, Nelore 27, Canchim; 27, Holandês), com peso médio inicial de $250 \mathrm{~kg}$ e média de 15 meses de idade. Os animais foram alojados em baias $(3 \times 11 \mathrm{~m})$ cobertas, com piso, cocho e bebedouro revestidos de concreto. Foram distribuídos três animais por baia, em um total de 27 baias. Os animais foram previamente everminados e receberam uma dose de complexo vitamínico ADE na fase de adaptação às dietas e às instalações experimentais.

Os animais foram alimentados com dietas contendo bagaço de cana-de-açúcar in natura (BIN) como volumoso $(20 \%)$ e $80 \%$ de concentrado (Tabela 1 ). Os tratamentos constataram da substituição total da fonte de proteína verdadeira (farelo de soja - FS), em uma dieta deficiente em proteína degradável no rúmen (PDR) segundo o modelo do National Research Council (1996), por uréia ou amiréia (A-150S - fonte de $\mathrm{N}$ não protéico de suposta liberação gradativa de N). As duas fontes foram utilizadas em uma dieta adequada em PDR. Os tratamentos foram formulados de modo que constituíssem dietas isoprotéicas e isoenergéticas, utilizando o programa do National Research Council (1996) de bovinos de corte. A composição da dieta em ingredientes e nutrientes é apresentada nas Tabelas 1 e 2.

As fontes de uréia utilizadas foram a uréia (adubo convencional) e a uréia convencional extrusada, utili- zando-se o milho como fonte de amido (Amiréia 150S, Pajoara Indústria e Comércio, Campo Grande, MS).

Os concentrados foram misturados previamente em um misturador horizontal (capacidade de $250 \mathrm{~kg}$ ). Por ocasião do fornecimento da alimentação, o BIN e o concentrado, nas suas respectivas proporções, foram misturados, utilizando um vagão para ração completa (marca Siltomac, com capacidade de $1.800 \mathrm{~kg}$ ) e fornecidos uma única vez ao dia como ração completa, às $18 \mathrm{~h}$.

O período experimental durou 118 dias e os primeiros 20 dias foram destinados ao processo de adaptação dos

Tabela 1. Composição em ingredientes e composição química das dietas (\% da MS).

\begin{tabular}{lccc}
\hline Ingredientes & \multicolumn{3}{c}{ Tratamentos } \\
\cline { 2 - 4 } & FS & Uréia & A-150S \\
\hline Bagaço de cana in natura (BIN) & 20,5 & 20,5 & 20,5 \\
Milho moído & 27,5 & 33,2 & 30,9 \\
Polpa ć́trica & 33,1 & 41,0 & 41,0 \\
Farelo de soja (FS) & 16,5 & - & - \\
Uréia & - & 2,46 & - \\
Amiréia (A-150S) & - & - & 4,78 \\
Mistura mineral(1) & 1,37 & 1,37 & 1,37 \\
Cloreto de potássio & - & 0,41 & 0,41 \\
Bicarbonato de sódio & 1,09 & 1,09 & 1,09 \\
\hline Composição química & & & \\
MS (\% da matéria natural) & 79,2 & 79,3 & 79,3 \\
Proteína bruta & 12,8 & 13,1 & 13,1 \\
Fibra em detergente neutro & 34,3 & 36,1 & 33,9 \\
Fibra em detergente ácido & 25,4 & 27,5 & 26,4 \\
Matéria mineral & 5,5 & 5,5 & 5,7 \\
Extrato etéreo & 2,3 & 2,5 & 2,4 \\
\hline
\end{tabular}

(1) Composição do farelo de soja (FS): NNP, 1,74\%; Ca, 0,012\%; P, 4\%; $\mathrm{S}, 2,7 \%$; Cu, $750 \mathrm{ppm}$; I, $40 \mathrm{ppm}$; Mn, $1.500 \mathrm{ppm} ; \mathrm{Se}, 10 \mathrm{ppm}$; $\mathrm{S}, 2,7 \%$; $\mathrm{Cu}, 750 \mathrm{ppm} ; \mathrm{I}, 40 \mathrm{ppm}$; Mn, $1.500 \mathrm{ppm} ; \mathrm{Se}, 10 \mathrm{ppm}$;
$\mathrm{Zn}, 2.250 \mathrm{ppm}$; vit.A, $300.000 \mathrm{UI} / \mathrm{kg}$; vit.D3, $20.000 \mathrm{UI} / \mathrm{kg}$; $\mathrm{Zn}, 2.250 \mathrm{ppm}$; vit.A, $300.000 \mathrm{UI} / \mathrm{kg}$; vit.D $3,20.000 \mathrm{UI} / \mathrm{kg}$;
vit.E, $3.500 \mathrm{UI} / \mathrm{kg}$; Rumensin, $2 \%$; composição da uréia e A-150S: NNP, 4,35\%; Ca, 0,012\%; P, 10\%; S, 7,1\%; Mg, 2,0\%; Cu, $750 \mathrm{ppm}$; I, 40 ppm; Mn, $1.500 \mathrm{ppm}$; Se, 10 ppm; Zn, $2.250 \mathrm{ppm}$; vit.A, $300.000 \mathrm{UI} / \mathrm{kg}$; vit.D3, $20.000 \mathrm{UI} / \mathrm{kg}$; vit.E, 3.500UI/kg; Rumensin, $2 \%$.

Tabela 2. Composição das frações nitrogenadas das dietas $(\% \text { da MS })^{(1)}$

\begin{tabular}{lccc}
\hline Variáveis & FS & Uréia & A-150S \\
\hline PB (\%) & 12,8 & 13,1 & 13,1 \\
Pbsol (\% da PB) & 13,4 & 59,3 & 61,4 \\
PBIDN (\% da PB) & 19,1 & 16,8 & 20,2 \\
PBIDA (\% da PB) & 12,6 & 11,8 & 11,7 \\
PDR $(2)$ (\% da PB) & 58,4 & 75,3 & 75,3 \\
PDR (\% da MS) & 7,5 & 9,9 & 9,9 \\
\hline
\end{tabular}

PDR (\% da MS) $\quad 9,9$ (1)FS: farelo de soja; A-150S: amiréia; PB: proteína bruta; Pbsol: proteína bruta solúvel; PBIDN: proteína bruta insolúvel em detergente neutro; PBIDA. proteina bruta insolúvel em detergente ácido, PDR. proteína bruta degradável no rúmen. 1 Estimada pelo modelo do National Research Council (1996) nível 1; para BIN utilizou-se 25\% (Fox et al., 
animais às instalações e às dietas experimentais. $O$ restante do período foi segmentado em quatro subperíodos: três de 28 dias e um de 14 dias. Os animais foram pesados no final do período de adaptação e no final de cada subperíodo experimental. As pesagens dos animais foram feitas com jejum de 16 horas.

Os dados de consumo de matéria seca (MS) por ani$\mathrm{mal} /$ dia foram obtidos pela diferença entre a quantidade de MS fornecida e a MS da sobra. A quantidade de MS fornecida foi determinada diariamente em balança eletrônica do vagão para ração completa. A quantidade de alimento oferecido foi ajustada diariamente com base nas sobras do dia anterior, objetivando um mínimo de sobra, registrada semanalmente. Durante o período experimental, foram amostradas as sobras e os alimentos oferecidos uma vez por semana, os quais foram compostos por subperíodo e tratamento.

As amostras foram conservadas a $-10^{\circ} \mathrm{C}$ até serem descongeladas e secadas em estufa com ventilação forçada $\left(55^{\circ} \mathrm{C}\right)$ por 72 horas. A seguir foram moídas em moinhos tipo Willey, primeiramente em peneira de $2 \mathrm{~mm}$ e após em peneiras de $1 \mathrm{~mm}$ e, posteriormente, secadas por 12 horas a $105^{\circ} \mathrm{C}$ para determinação de MS, de acordo com Silva (1990); matéria mineral (MM), extrato etéreo (EE) e proteína bruta (PB), de acordo com Association of Official Analytical Chemists (1990); fibra detergente neutro (FDN) e fibra detergente ácido (FDA), de acordo com Van Soest et al. (1991), não seqüencial, utilizando amilase e sulfito de sódio na determinação da fibra em detergente neutro.

O delineamento experimental utilizado foi o de blocos casualizados, arranjados de acordo com peso inicial e raça, constituídos de três animais por baia e nove baias por tratamento. Os dados foram analisados pelo procedimento MIXED do programa estatístico SAS Institute (1991). Foi utilizado o seguinte modelo estatístico: $\mathrm{Y}_{\mathrm{ijk}}=\mathrm{M}+\mathrm{B}_{\mathrm{i}}+\mathrm{FP}_{\mathrm{j}}+\mathrm{P}_{\mathrm{k}}+\mathrm{FP}_{\mathrm{j}} \mathrm{xP} \mathrm{P}_{\mathrm{k}}+\mathrm{E}_{\mathrm{ijk}}$

em que $\mathrm{M}$ é a média geral; $\mathrm{B}_{\mathrm{i}}$ é o efeito do bloco; $\mathrm{FP}_{\mathrm{j}}$ é $\mathrm{o}$ efeito da fonte protéica; $\mathrm{P}_{\mathrm{k}}$ é o efeito de período; $\mathrm{FP}_{\mathrm{j}} \mathrm{xP}_{\mathrm{k}}$ são as interações entre a fonte protéica e o período; $\mathrm{E}_{\mathrm{ijk}}$ é o efeito aleatório.

Este modelo foi utilizado na análise de todas as variáveis, exceto no consumo de MS, em que se utilizou semana no lugar de período. $\mathrm{O}$ efeito de blocos foi considerado aleatório. Os dados foram submetidos à análise de variância e as médias comparadas pelo teste de Tukey a $5 \%$ de probabilidade.

\section{Resultados e Discussão}

O tratamento com farelo de soja apresentou menor consumo de MS, ganho de peso e pior conversão alimentar $(\mathrm{P}<0,05)$, em relação aos demais tratamentos (Tabela 3).

O menor consumo de MS no tratamento com farelo de soja deve ter ocorrido em virtude da menor fração de proteína degradável no rúmen (Tabela 2). Alterações no consumo ocorrem quando a quantidade de proteína dietética não é suficiente para produzir quantidade adequada de amônia ruminal. Segundo os modelos National Research Council (1996) e CNCPS (Fox et al., 2000), o balanço de $\mathrm{N}$ no rúmen foi negativo no tratamento com farelo de soja e positivo nos demais. Ferrell et al. (2001) constataram que a suplementação com proteína não degradável no rúmen promove benefícios para o animal, mas só após satisfazer as exigências em PDR. Os resultados encontrados neste trabalho corroboram os desses autores.

As bactérias fermentadoras de carboidratos fibrosos utilizam amônia como única fonte de nitrogênio. Estas bactérias fermentadoras são altamente prejudicadas quando ocorre deficiência de $\mathrm{N}$ degradável no rúmen, levando a um menor desaparecimento dos carboidratos fibrosos, diminuindo assim a taxa de passagem e, e conseqüentemente, o consumo de MS (Russel et al., 1992; Tedeschi et al., 2000). O menor consumo de MS proporcionou um menor aporte energético para o animal e, consequientemente, um menor ganho de peso diário.

As dietas com NNP (uréia ou amiréia) apresentaram $70 \%$ da PDR proveniente do NNP (Tabelas 1 e 2), proporcionando um maior consumo e desempenho dos animais (Tabela 3). Animais pastejando forragem de baixa qualidade $(\mathrm{PB}=2,4 \%$ e $\mathrm{FDN}=73,0 \%)$ diminuíram o consumo quando a uréia ( $3,2 \%$ do suplemento) contri-

Tabela 3. Desempenho de bovinos de corte confinados suplementados com diferentes fontes nitrogenadas ${ }^{(1)}$

\begin{tabular}{lrrrr}
\hline Variáveis & \multicolumn{1}{c}{ FS } & \multicolumn{1}{c}{ Uréia } & A-150S & EPM \\
\hline Peso inicial $(\mathrm{kg})$ & $279,8 \mathrm{a}$ & $265,4 \mathrm{a}$ & $269,4 \mathrm{a}$ & 5,47 \\
Peso final $(\mathrm{kg})$ & $367,3 \mathrm{~b}$ & $374,6 \mathrm{a}$ & $374,2 \mathrm{a}$ & 5,89 \\
$\mathrm{CMS}(\mathrm{kg} / \mathrm{d})$ & $6,56 \mathrm{~b}$ & $7,18 \mathrm{a}$ & $6,97 \mathrm{a}$ & 0,42 \\
$\mathrm{PV}(\%)$ & $1,98 \mathrm{~b}$ & $2,19 \mathrm{a}$ & $2,14 \mathrm{a}$ & 0,11 \\
$\mathrm{PV}(0,75 / \mathrm{g} / \mathrm{kg})$ & $85,2 \mathrm{~b}$ & $92,7 \mathrm{a}$ & $90,6 \mathrm{a}$ & 4,79 \\
$\mathrm{GPV}(\mathrm{kg} / \mathrm{d})$ & $0,889 \mathrm{~b}$ & $1,114 \mathrm{a}$ & $1,088 \mathrm{a}$ & 0,05 \\
$\mathrm{CA}(\mathrm{kg} \mathrm{MS} / \mathrm{kg}$ ganho) & $7,3 \mathrm{a}$ & $6,5 \mathrm{~b}$ & $6,7 \mathrm{~b}$ & 0,39 \\
\hline
\end{tabular}

${ }^{(1)}$ Médias seguidas da mesma letra, na linha, não diferiram entre si pelo teste Tukey a 5\% de probabilidade; FS: farelo de soja; A-150S: amiréia; CMS: consumo de matéria seca; GPV: ganho de peso vivo; PV: peso vivo; CA: conversão alimentar; EPM: erro padrão da média. 
buiu com mais de $40 \%$ da proteína degradável no rúmen. Animais confinados recebendo feno de sorgo $(\mathrm{PB}=4,4 \%$ e $\mathrm{FDN}=58,9 \%)$ como volumoso e uma dieta com até $60 \%$ da PDR proveniente da uréia $(4,8 \%$ do concentrado) não alteraram o consumo (Köster et al. 2002). O limite de inclusão de uréia na dieta parece estar relacionado com a dieta (qualidade da forragem, tipo de carboidrato e outros) e o manejo (pastejo, confinamento e outros) (Köster et al., 2002).

Thompson et al. (1972), Schmidt et al. (1973), Seixas et al. (1999) e Teixeira et al. (2000), utilizando novilhos em crescimento, obtiveram resultados similares aos deste trabalho, no tocante ao consumo de matéria seca, quando compararam amiréia e uréia. Por sua vez, não verificaram alterações no consumo de MS quando avaliaram fontes de NNP (uréia e amiréia) e farelo de soja (Thompson et al., 1972; Schmidt et al., 1973; Teixeira et al., 2000) ou farelo de algodão (Seixas et al., 1999). Outros autores também não observaram alterações no consumo de MS entre farelo de soja, uréia e amiréia (Silva et al., 1994) e farelo de algodão, uréia e amiréia (Salman et al., 1997; Ezequiel et al., 2001) em borregos. Houve uma redução no consumo de matéria seca no tratamento com farelo de soja neste trabalho.

O tratamento com farelo de soja, mesmo com 7,5\% de PDR (\% da MS), não foi suficiente para maximizar o consumo, o ganho e a eficiência alimentar. O tratamento com NNP (PDR adequada) continha 9,9\% de PDR (\% da MS; Tabela 2), e pode ter sido responsável por maior consumo de MS, ganho e melhor conversão alimentar (Tabela 3), demonstrando que os valores do National Research Council (1996) são adequados para estimar a exigência de PDR neste tipo de dieta. Milton et al. (1997), Shain et al. (1998) e Cooper et al. (2002) observaram que a exigência de PDR (\% da MS) estimada pelo National Research Council (1996), níve 1 , está correta nos animais em terminação com dietas base de milho laminado. No entanto, Cooper et al. (2002) observaram que a estimativa do National Research Council (1996) para PDR é subestimada em dietas à base de milho de alta umidade e de floculado para animais em terminação.

Stiles et al. (1970) sugeriram que a extrusão provoca a incorporação da uréia na estrutura do amido, promovendo melhor aceitabilidade do concentrado. Assim Salman et al. (1997) sugeriram que a amiréia pode aumentar a aceitação da uréia nas rações, o que não ocor reu neste trabalho, cujo consumo de MS nos tratamentos com uréia e com amiréia foi semelhante.
Bartley \& Deyoe (1975) sumarizaram diversos trabalhos, totalizando 12 comparações de ganho de peso diário e conversão alimentar em novilhos em terminação, recebendo uréia ou amiréia, e concluíram que em nenhuma das avaliações ocorreu diferença, e as médias de todas as comparações foram iguais $\left(1,25 \mathrm{~kg}\right.$ animal $\left.^{-1} \mathrm{~d}^{-1}\right)$ em relação à uréia e amiréia. Os resultados dos trabalhos revisados por estes autores estão de acordo com os dados deste trabalho.

O desempenho dos animais alimentados com amiréia ou uréia foi similar, provavelmente pelo fato a amiréia ter liberado muito rapidamente o $\mathrm{N}$, não exercendo proteção do $\mathrm{N}$ prontamente solúvel, ou de o sistema de reciclagem de $\mathrm{N}$ no rúmen se adaptar facilmente à rapidez da liberação de amônia pelas fontes de $\mathrm{N}$ não protéico, desde que as concentrações não atinjam níveis tóxicos (Owens \& Zinn, 1988).

Teixeira et al. (1999), avaliando a degradabilidade da proteína bruta da amiréia com diferentes granulometrias, observaram que o processamento físico da amiréia (quebra ou moagem) altera a fração solúvel da proteína (liberação de $\mathrm{N}$ ), tornando a fração solúvel da proteína da amiréia moída muito próxima de uma mistura de uréia mais milho sem extrusão. Neste trabalho, utilizou-se amiréia com alto equivalente protéico e na forma moída, o que pode ter contribuído para sua equivalência com a uréia.

O benefício da amiréia reside na liberação gradativa de N no rúmen. Isto não ocorre, ou ocorre muito pouco, se a amiréia estiver na forma moída ou de pellet quebrado e esta alta solubilidade pode levar o animal a uma intoxicação com amônia, dependendo da quantidade de amiréia na dieta. A amiréia na forma de pellet, apesar de diminuir a solubilidade do $\mathrm{N}$, tem concentração elevada quando comparada às fontes de proteína verdadeira. No entanto, a amiréia na forma de pellet pode apresentar segregação nas misturas, dificultando a sua utilização.

\section{Conclusões}

1. Atender às exigências de proteína degradável no rúmen via uréia ou amiréia, em dietas com alto teor de concentrado, proporciona desempenhos melhores do que a utilização de farelo de soja.

2. O consumo de matéria seca, ganho de peso e conversão alimentar de animais alimentados com amiréia moída e uréia convencional são similares. 
3. O bagaço de cana-de-açúcar in natura promove bom desempenho quando utilizado como única fonte de volumoso (20\% da MS) em dietas com alto teor de concentrado ( $80 \%$ da MS).

\section{Referências}

ASSOCIATION OF OFFICIAL ANALYTICAL CHEMISTS (Arlington, Estados Unidos). Official Methods of Analysis. $15^{\text {th }}$ ed. Arlington, 1990. v.1.

BARTLEY, E.E.; DEYOE, C.W. Starea as a protein replacer for ruminants - review of 10 years of research. Feedstuffs, v.47, p.42 44, 1975.

BLAXTER, K.L. The energy metabolism of ruminants. London: Hutchinson, 1962. 329p.

BULLE, M.L.M.; RIBEIRO, F.G.; LEME, P.R.; TITTO, E.A.L.; LANNA, D.P.D. Desempenho de tourinhos cruzados em dietas de alto teor de concentrado com bagaço de cana-de-açúcar como único volumoso. Revista Brasileira de Zootecnia, v.31, p.444-450, 2002 COOPER, R.J.; MILTON, C.T.; KLOPFENSTEIN, T.J.; JORDON, D.J. Effect of corn processing on degradable intake protein requirement of finishing cattle. Journal of Animal Science, v.80, p.242-247, 2002.

EZEQUIEL, J.M.B.; MATARAZZO, S.V.; SALMAN, A.K.D.; MARTINS JÚNIOR, A.P.; SOARES, W.V.B.; SEIXAS, J.R.C. Digestibilidade aparente da energia e da fibra de dietas para ovinos contendo uréia, amiréia ou farelo de algodão. Revista Brasileira de Zootecnia, v.30, p.231-235, 2001.

FERRELL, C.L.; FREETLY, H.C.; GOETSCH, A.L.; KREIKEMEIER, K.K. The effect of dietary nitrogen and protein on feed intake, nutrient digestibility, and nitrogen flux across the portal-drained viscera and liver of sheep consuming high-concentrate diets ad libitum. Journal of Animal Science, v.79, p.1322-1328, 2001.

FOX, D.G.; TYLUTKI, T.P.; AMBURGH, M.E. van; CHASE, L.E.; PELL, A.N.; OVERTON, T.R.; TEDESCHI, L.O RASMUSSEN, C.N.; DURBAL, V.M. The net carbohydrate and protein system for evaluating herd nutrition and nutrient excretion. Ithaca: Cornell University, 2000. 235p

HENRIQUE, W.; LEME, P.R.; LANNA, D.P.D.; ALLEONI, G.F.; COUTINHO FILHO, J.L.V.; BELTRAME FILHO, J.A. Avaliação do milho úmido com bagaço de cana ou silagem de milho na engorda de bovinos - I: Desempenho animal e características de carcaça. In: REUNIÃO ANUAL DA SOCIEDADE BRASILEIRA DE ZOOTECNIA, 36., 1999. Porto Alegre. Anais. Porto Alegre: Sociedade Brasileira de Zootecnia, 1999. p.307.

KÖSTER, H.H.; WOODS, B.C.; COCHRAN, R.C.; VANZANT, E.S.; TITGEMEYER, E.C.; GRIEGER, D.M.; OLSON, K.C.; STOKKA, G. Effect of increasing proportion of supplemental N from urea in prepartum supplements on range beef cow performance and on forage intake and digestibility by steers fed low-quality forage. Journal of Animal Science, v.80, p.1652-1662, 2002.
MILTON, C.T.; BRANDT JUNIOR, R.T.; TITGEMEYER, E.C. Urea in dry-rolled corn diets: finishing steer performance, nutrient digestion, and microbial protein production. Journal of Animal Science, v.75, p.1415-1424, 1997.

NATIONAL RESEARCH COUNCIL (Washington, Estados Unidos). Nutrient Requirements of Beef Cattle. $7^{\text {th }}$ ed. Washington: National Academy Press, 1996. 242p.

OWENS, F.N.; ZINN, R. Protein metabolism of ruminant animal. In: $\mathrm{CHURCH}$, D.C. (Ed.). The ruminant animal: digestive physiology and nutrition. Englewood Cliffs: Simon \& Schuster, 1988. p.227-249.

RUSSEL, J.B.; O'CONNOR, J.D.; FOX, D.G.; VAN SOEST, P.J.; SNIFFEN, C.J. A net carbohydrate and Protein System for evaluating cattle diets - I: Ruminal fermentation. Journal of Animal Science, v.70, p.3551-3561, 1992.

SALMAN, A.K.D.; MATARAZZO, S.V.; EZEQUIEL, J.M.B.; KRONKA, S.N.; SEIXAS, J.R.C.; SOARES, W.V.B.; MARTINS JÚNIOR, A.P. Estudo do balanço nitrogenado e da digestibilidade da matéria seca e proteína de rações, para ovinos, suplementadas com amiréia, uréia ou farelo de algodão. Revista Brasileira de Zootecnia, v.26, p.179-185, 1997

SAS INSTITUTE SAS/STAT User's guide. Cary, 1991. 1028p. SCHMIDT, S.P.; JORGENSE, N.A.; BENEVENG, N.J.; BRUNGARD, V.H. Comparison of soybean-meal, formaldehyde treated soybean-meal, urea and starea for steers. Journal of Animal Science, v.37, p.1233-1237, 1973.

SEIXAS, J.R.C.; EZEQUIEL, J.M.B.; ARAÚJO, W.D.; RESENDE, F.D.; MARTINS JÚNIOR, A.; KRONKA, S.N.; SILVA, L.D.F. da; DOURADO, J.B.; SOARES, W.V.B. Desempenho de bovinos confinados alimentados com dietas à base de farelo de algodão, uréia ou amiréia. Revista Brasileira de Zootecnia, v.28, p.432-438, 1999. SHAIN, D.H.; STOCK, R.A.; KLOPFENSTEIN, T.J.; HEROLD, D.W. Effect of degradable intake protein level on fishing cattle performance and ruminal metabolism. Journal of Animal Science, v.76, p.242-248, 1998

SILVA, D.J. Análise de alimentos: métodos químicos e biológicos. Viçosa: UFV, 1990. 166p

SILVA, J.F.C.; PEREIRA, J.C.; VALADARES FILHO, S.C : VILELA, L.M.R.; LOMBARDI, C.T. Valor nutritivo da palha de arroz suplementada com amiréia, fubá+uréia e farelo de soja. Pesquisa Agropecuária Brasileira, v.29, p.1475-1481, 1994

STILES, D.A.; BARTLEY, E.E.; MEYER, R.M.; DEYOE, C.V.; PFOST, H.B. Feed processing. VII. Effect of an expansion-processed mixture of grain and urea (starea) on rumen metabolism in cattle and on urea toxicity. Journal of Dairy Science, v.53, p.1436-1447, 1970

TEDESCHI, L.O.; FOX, D.G.; RUSSELL, J.B. Accounting for the effects of a ruminal nitrogen deficiency within the structure of the Cornell Net carbohydrate and protein system. Journal of Animal Science, v.78, p.1648-1658, 2000. 
TEIXEIRA, J.C. DELGADO, E.F.; CORREA, E.M.; MORON, I.R. Cinética da digestão ruminal da amiréia $45-\mathrm{S}$ em vacas da raça holandesa. Ciência e Agrotecnologia, v.23, p.719-723, 1999.

TEIXEIRA, J.C.; PEREZ, J.R.O.; MORON, I.R.; VEIGA, R.D.; SANTOS, R.M. Aproveitamento do macho leiteiro utilizando dieta à base de amirea 45S. II. Desempenho. Ciência e Agrotecnologia, v.24, p.203-207, 2000.
THOMPSON L H · WISE M B · BARRICK, E R · HARVEY, R W . Starea, urea and sulfur in beef-cattle rations. Journal of Animal Science, v.35, p.474-480, 1972.

VAN SOEST, P.J.; ROBERTSON, J.B.; LEWIS, B.A. Methods for dietary fiber, neutral detergent fiber, and nonstarch polysaccharides in relation to animal nutrition. Journal of Dairy Science, v.74, p.3583-3597, 1991.

Recebido em 7 de outubro de 2003 e aprovado em 14 de abril de 2004 